\title{
PENINGKATAN HASIL BELAJAR MAHASISWA PGSD UN PGRI KEDIRI DENGAN MODUL BERBASIS KONFLIK KOGNITIF PADA MATERI MENYUSUN PERANGKAT PEMBELAJARAN IPA SD
}

\author{
Linda Rachmawati \& Bagus Amirul Mukmin \\ bagusamirulm@gmail.com \\ Pendidikan Guru Sekolah Dasar \\ Fakultas Keguruan dan Ilmu Pendidikan \\ Universitas Nusantara PGRI Kediri
}

\begin{abstract}
In science lesson of elementary school, there are some problems related to the students' learning outcomes that are still low. This is proved by the average score of students is 69 and viewed from the percentage of students' learning achievement is $38 \%$. This is because the students understanding related to the preparation of teaching administrations are still lack. Another factor that influences is lecturer teaching method is not appropriate. The learning that is applied so far is teacher-centered, so that students are more passive and less involved in learning activity. The objective of this study is to improve the students learning outcomes of science lesson of elementary school. This research used classroom action research with the stages of planning, implementation, observation, and reflection. This research subjects are A class of $6^{\text {th }}$ semester of Primary School Teacher Education Department, Nusantara PGRI Kediri University. The data of this study are collected by observation and test techniques. The results showed that the average increase in student learning outcomes from pre-cycle activities of 69 , in the first cycle 73 , and on the second cycle increased to 83 . While the percentage of students' learning achievement also increased from pre-cycle activity by $38 \%$, in the first cycle to $59 \%$, and in second cycle reached $87 \%$. Based on the results study, it can be concluded that the module based on cognitive conflict can improve the understanding and learning outcomes of students in Science Lesson of Elementary School of Primary School Teacher Education Department, Nusantara PGRI Kediri University.
\end{abstract}

Keywords: learning outcomes, module based on cognitive conflict.

\begin{abstract}
Abstrak: Pada perkuliahan Pembelajaran IPA SD ditemukan berbagai persoalan terkait dengan hasil belajar mahasiswa yang masih rendah. Hal ini dibuktikan dengan nilai rata-rata mahasiswa sebesar 69 dan jika ditinjau dari persentase ketuntasan klasikal, hasil belajar mahasiswa sebesar 38\%. Hal tersebut dikarenakan pemahaman mahasiswa terkait penyusunan perangkat pembelajaran masih kurang. Faktor lain yang memengaruhi adalah cara mengajar dosen yang kurang tepat. Pembelajaran yang diterapkan selama ini berpusat pada guru, sehingga siswa lebih pasif dan kurang terlibat dalam pembelajaran. Tujuan penelitian ini yaitu untuk meningkatkan hasil belajar mata kuliah pembelajaran IPA SD pada mahasiswa. Jenis penelitian yang digunakan yaitu penelitian tindakan kelas (PTK) dengan tahapan perencanaan, pelaksanaan, observasi, dan refleksi. Subyek dalam penelitian ini adalah mahasiswa semester 6 kelas A program studi Pendidikan Guru Sekolah Dasar, Universitas Nusantara PGRI Kediri. Data penelitian ini dikumpulkan dengan teknik observasi dan tes. Hasil penelitian menunjukan bahwa adanya peningkatan rata-rata hasil belajar mahasiswa dari kegiatan pra siklus sebesar 69 , pada siklus I sebesar 73, dan pada
\end{abstract}


Linda \& Bagus, Peningkatan Hasil Belajar Mahasiswa...

siklus II meningkat menjadi 83. Untuk persentase ketuntasan klasikal hasil belajar mahasiswa juga mengalami peningkatan dari kegitan prasiklus sebesar 38\%, pada siklus I menjadi 59\%, dan pada siklus II mencapai $87 \%$. Berdasarkan hasil penelitian dapat disimpulkan bahwa modul berbasis konflik kognitif dapat meningkatkan pemahaman dan hasil belajar mahasiswa pada mata kuliah pembelajaran IPA SD Program Studi Pendidikan Guru Sekolah Dasar Universitas Nusantara PGRI Kediri.

Kata Kunci: hasil belajar, modul berbasis konfik kognitif.

\section{PENDAHULUAN}

Pada pogram studi PGSD Universitas Nusantara PGRI Kediri, mempunyai berbagai mata kuliah yang harus ditempuh oleh mahasiswa untuk mencapai kompetensi yang diharapkan sebagai guru SD yang baik. Diantara mata kuliah tersebut salah satunya yaitu Pembelajaran IPA di SD. Mata kuliah tersebut mengharapkan ketercapaian soft skill yaitu mahasiswa memiliki komitmen (sikap) dan tanggung jawab dalam melaksanakan, dan mengembangkan pembelajaran untuk meningkatkan mutu pembelajaran di sekolah dasar. Untuk itu setelah menempuh mata kuliah tersebut diharapkan mahasiswa dapat kreatif dalam melaksanakan dan mengembangkan pembelajaran untuk meningkatkan hasil belajar siswanya kelak.

Berkaitan dengan pernyataan di atas, tim peneliti melakukan observasi pada kegiatan pembelajaran/perkuliahan mahasiswa PGSD UN PGRI Kediri. Tepatnya pada mahasiswa semester 6 saat perkuliahan Pembelajaran IPA SD. Pada perkuliahan tersebut ditemukan berbagai persoalan terkait dengan hasil belajar mahasiswa yang masih rendah. Hal ini dibuktikan dengan nilai rata-rata mahasiswa sebesar 69, jika ditnjau dari persentase ketuntasan klasikal hasil belajar mahasiswa sebesar 38\%. Hal tersebut dikarenakan pemahaman mahasiswa terkait penyususnan perangkat pembelajaran masih kurang, faktor lain yang memengaruhi adalah cara mengajar dosen yang kurang tepat. Pembelajaran yang diterapkan slama ini berpusat pada guru, sehingga siswa lebih pasif dan kurang terlibat dalam pembelajaran.

Salah satu alternatif pemecahan masalah tersebut dapat dilakukan dengan mengembangkan bahan ajar yang sesuai dengan teori, sistem belajar aktif, dan mampu menjembatani antara pemahaman awal yang mungkin kurang tepat untuk membentuk pemahaman baru yang lebih tepat yakni berupa modul. Dalam buku Pedoman Umum Pengembangan Bahan Ajar (2008) yang diterbitkan oleh Depdiknas, modul diartikan sebagai sebuah buku yang ditulis dengan tujuan agar peserta didik dapat belajar secara mandiri tanpa atau dengan bimbingan guru, modul mahasiswa bisa belajar dengan kecepatannya masing-masing.

Selain modul pembelajaran, untuk melaksanakan pembelajaran yang baik diperlukan juga sebuah model pembelajaran yang relevan dengan bahan ajar dan peserta didik. Salah satu teori yang dikemukakan Akbar (2011: 188) bahwa ketika KTSP nya berorientasi konstruktivisme dan competence based maka sumber dan media, modelmodel, bahan ajar, dan penilaian pembelajaran yang dikembangkan dan disusun 
Linda \& Bagus, Peningkatan Hasil Belajar Mahasiswa...

hendaknya juga berorientasi pada teori-teori konstruktivistik. Untuk meningkatkan hasil belajar diperlukan sebuah modul berbasis konflik kognitif yang disusun dengan orientasi pada teori konstruktivistik agar pemahaman siswa lebih baik.

Konflik kognitif merupakan salah satu bentuk model pembelajaran inovatif yang menekankan pada partisipasi siswa untuk mencari sendiri informasi materi pelajaran yang akan dipelajari melalui bahan-bahan yang tersedia (Suastra, 2009:164). Konflik kognitif diberikan kepada mahasiswa yang hendak mengembangkan perangkat pembelajaran agar dapat mengubah miskonsepsi- miskonsepsi menuju konsepsi yang benar melalui strategi pengubahan konseptual yang tepat. Peneliti memilih model konflik kognitif sebagai bentuk penyajian dari modulnya.

Berdasarkan latar belakang di atas peneliti memilih untuk menerapkan modul berbasis konflik kognitif yang diharapkan mampu meningkatkan hasil belajar mahasiswa, dengan demikian mahasiswa dapat memperoleh pengetahuan yang lebih bermakna serta memaksimalkan hasil belajar mereka. Adapun judul yang akan digunakan dalam penelitian ini yakni "Peningkatan Hasil Belajar Mahasiswa PGSD UN PGRI Kediri Dengan Modul Berbasis Konflik Kognitif Pada Materi Menyusun Perangkat Pembelajaran IPA SD”.

\section{METODE}

\section{Jenis Penelitian}

Penelitian ini tergolong penelitian tindakan kelas (classroom action research) yang digunakan untuk memperbaiki mutu pelajaran bertujuan untuk meningkatkan hasil belajar mahasiswa semester 6 UN PGRI Kediri. Materi pembelajaran yang diangkat peneliti adalah menyusun perangkat pembelajaran IPA SD. Penelitian tindakan kelas (PTK) adalah proses investigasi terkendali untuk menyelesaikan permasalahan yang ada di kelas. Wahidmurni (2008: 15) menyatakan bahwa PTK dapat diartikan sebagai upaya atau tindakan yang dilakukan oleh guru atau peneliti untuk memecahkan masalah pembelajaran melalui kegiatan pembelajaran. Proses penyelesaian permasalahan yang berkaitan dengan hasil belajar tersebut dilakukan secara bersiklus dengan tujuan untuk meningkatkan kualitas proses dan hasil belajar di kelas (Akbar, 2009: 65). Dalam penelitian PTK terdapak empat langkah meliputi tahap-tahap perencanaan, pelaksanaan, observasi, dan refleksi di tiap siklusnya, Mulyasa (2010: 73).

Penelitian ini akan dilaksanakan dalam beberapa siklus, dimana setiap siklusnya terdiri dari perencanaan, pelaksanaan, observasi, dan refleksi. Pada Siklus I dan siklus II menggunakan materi yang sama tiap siklusnya, Siklus II dilakukan jika belum mencapai peningkatan yang signifikan pada siklus I. Penelitian ini dikatakan berhenti apabila pada siklus II sudah memenuhi kriteria ketuntasan klasikal kelas sebesar $\geq 80 \%$. Apabila siklus II belum mencapai target yang telah ditentukan maka akan dilanjutkan ke siklus berikutnya. Subyek dalam penelitian ini adalah mahasiswa semester 6 kelas A program studi PGSD, Universitas Nusantara PGRI Kediri yang berjumlah 37 orang. 
Linda \& Bagus, Peningkatan Hasil Belajar Mahasiswa...

\section{Metode Pengumpulan Data}

\section{Teknik Tes}

Teknik tes tertulis merupakan pengumpulan data melalui pemberian tes, yaitu evaluasi secara individu yang dilaksanakan pada akhir pembelajaran dan diberikan kepada seluruh siswa yang dijadikan subyek dalam penelitian.

\section{Metode Observasi}

Metode observasi yaitu pengumpulan data dengan pengamatan langsung mengenai penilaian praktek atau implementasidalam proses pembelajaran yang dilakukan. Dalam penelitian ini peneliti bertugas untuk mengamati dan mengobservasi kegiatan pembelajaran. Metode analisis data yang digunakan untuk menganalisis data dalam penelitian ini adalah metode statistik deskriptis kualitatif dan kuantitatif. Metode kualitatif digunakan untuk menganalisis data berupa hasil observasi, sedangkan metode kuantitatif digunakan untuk menganalisis data berupa hasil belajar siswa. Penentuan jumlah siklus didasarkan pada kriteria keberhasilan atau pencapaian target penelitian untuk ketuntasan hasil belajar siswa adalah $80 \%$ dari jumlah mahasiswa yang dapat mencapai KKM yaitu 75. Jika siklus I belum mencapai ketuntasan maka dilanjudkan ke siklus II. Jika pada siklus II sudah mencapai target yang di tentukan maka penelitian akan berhenti, tetapi jika belum mencapai akan di lanjudkan ke penelitian berikutnya.

\section{HASIL DAN PEMBAHASAN}

\section{Siklus I}

Pelaksanaan penelitian pada siklus I dilaksanakan dengan tahap perncanaan, pelaksanaan, observasi, dan refleksi. Berikut akan dipaparkan hasil dan pembahasan siklus I diawali dengan tahap perencanaan.

\section{Perencanaan Siklus I}

Pada tahap perencanaan kegiatan yang dilakukan peneliti adalah menyusun rencana pembelajaran yang akan digunakan dalam proses pembelajaran menyusun perangkat pembelajaran IPA SD. Pembelajaran pada siklus I dilakukan satu kali pertemuan dengan alokasi waktu 100 menit. Materi yang diajarkan sesuai dengan modul konflik kognitif untuk meningkatkan pengetahuan dan pemahaman siwa dalam penyususnan perangkat pembelajaran.

\section{Diskripsi Data Pelaksanaan Tindakan Siklus I}

Data yang diperoleh peneliti terkait dengan peningkatan hasil belajar mahasiswa PGSD dengan modul berbasis konflik kognitif terhadap kemampuan menyusun perangkat pembelajaran IPA SD pada siklus pertama mampu meningkatkan hasil belajar mahasiswa. Pada pra siklus rata-rata hasil belajar mahasiswa mencapai 64, siklus I nilai rata-rata 73 dan target penelitian 80 . Peningkatan hasil belajar mahasiswa dapat dilihat pada tabel 1 sebagai berikut : 
Linda \& Bagus, Peningkatan Hasil Belajar Mahasiswa...

Tabel 1. Hasil Belajar Mahasiswa PGSD Siklus I

\begin{tabular}{|c|c|c|c|}
\hline \multirow{2}{*}{ No } & \multirow{2}{*}{ Nama Siswa } & \multicolumn{2}{|c|}{ Nilai } \\
\hline & & Pra Siklus & Siklus I \\
\hline 1 & $\mathrm{AF}$ & 50 & 65 \\
\hline 2 & ATF & 40 & 59 \\
\hline 3 & APC & 55 & 63 \\
\hline 4 & CNA & 69 & 79 \\
\hline 5 & DPB & 75 & 81 \\
\hline 6 & DA & 61 & 76 \\
\hline 7 & FAM & 77 & 87 \\
\hline 8 & GR & 65 & 78 \\
\hline 9 & MR & 70 & 89 \\
\hline 10 & MA & 67 & 78 \\
\hline 11 & MAM & 81 & 92 \\
\hline 12 & MKA & 80 & 93 \\
\hline 13 & OLE & 71 & 78 \\
\hline 14 & RDS & 51 & 67 \\
\hline 15 & RFP & 67 & 84 \\
\hline 16 & SNF & 61 & 84 \\
\hline 17 & $\mathrm{~S}$ & 70 & 83 \\
\hline 18 & TZS & 60 & 83 \\
\hline 19 & WH & 60 & 81 \\
\hline 20 & $\mathrm{HS}$ & 87 & 100 \\
\hline 21 & RAR & 85 & 90 \\
\hline 22 & $\mathrm{MNH}$ & 67 & 79 \\
\hline 23 & PRW & 70 & 88 \\
\hline 24 & RANM & 68 & 73 \\
\hline 25 & SO & 76 & 87 \\
\hline 26 & SDP & 81 & 90 \\
\hline 27 & SAR & 83 & 96 \\
\hline 28 & ZKL & 81 & 86 \\
\hline 29 & SA & 85 & 96 \\
\hline 30 & ESD & 87 & 91 \\
\hline 31 & LI & 60 & 80 \\
\hline 32 & LKK & 67 & 76 \\
\hline 33 & $\mathrm{NH}$ & 50 & 87 \\
\hline 34 & $\mathrm{JK}$ & 83 & 90 \\
\hline 35 & WPW & 57 & 78 \\
\hline 36 & LR & 66 & 80 \\
\hline \multirow[t]{5}{*}{37} & DLP & 77 & 86 \\
\hline & Rata-rata & 69 & 73 \\
\hline & Tuntas & 14 & 22 \\
\hline & Tidak Tuntas & 23 & 15 \\
\hline & $\begin{array}{l}\text { Presentase } \\
\text { Ketuntasan }\end{array}$ & $38 \%$ & $59 \%$ \\
\hline
\end{tabular}

Dari tabel di atas peningkatan hasil belajar pada siklus I diperoleh rata-rata 69 pada pra siklus dan 73 pada siklus I. Jumlah siswa yang tuntas $\geq 75$ sebanyak 14 pada pra siklus dan 22 pada siklus I, sedangkan mahasiswa yang belum tuntas sebanyak 23 
Linda \& Bagus, Peningkatan Hasil Belajar Mahasiswa...

pada pra siklus dan 15 siswa pada tahap siklus I, sehingga presentase ketuntasan klasikal $38 \%$ pada pra siklus dan 59\% pada tahap siklus I. Peningkatan presentase ketuntasan hasil belajar pada kegiatan pra siklus $38 \%$ pada siklus I meningkat menjadi $59 \%$ dan target penelitian $80 \%$. Jadi ketuntasan hasil belajar siswa meningkat sebesar $21 \%$.

\section{Observasi Siklus I}

Berdasarkan hasil observasi yang dilakukan pada siklus I diketahui bahwa keterlaksanan pembelajaran di dalam kelas belum maksimal, pemanfaatan modul konflik kognitif belum berjalan dengan baik sesuai sintak yang telah ditentukan, sehingga kemampuan mahasiswa dalam menyusun perangkat pembelajaran belum maksimal.

\section{Refleksi Siklus I}

Kegitan refleksi bertujuan untuk mengetahui kelemahan dan kelebihan dari kegiatan yang sudah dilaksanakan. Pelaksanaan tindakan pada siklus I belum diperoleh hasil yang memuaskan. Hasil belajar mahasiswa belum mencapai target indikator keberhasilan yang sudah ditentukan yaitu $80 \%$. Hal ini disebabkan karena kurangnya kreatifitas dan pemahaman siswa dan kualitas pembelajaran dari dosen yang perlu ditingkatkan. Oleh karena itu, penelitian akan dilanjudkan pada siklus 2. Adapun hasil refleksi siklus I yaitu dosen perlu memperbaiki kualitas pembelajaran supaya hasil belajar meningkatkan.

\section{Siklus II}

Pelaksanaan penelitian pada siklus II ini sama dengan tahapan yang dilaksanakan pada siklus I dengan tahap perncanaan, pelaksanaan, observasi, dan refleksi. Berikut akan dipapaparkan hasil dan pembahasan siklus II diawali dengan tahap perencanaan.

\section{Perencanaan Siklus II}

Pada tahap perencanaan kegiatan yang dilakukan peneliti adalah memperbaiki kekurangan yang terjadi pada siklus I. Dosen akan memaksimalkan keterlaksanan pembelajaran di dalam kelas, selain itu pemanfaatan modul konflik kognitif lebih ditingkatkan dan disesuaikan dengan sintak yang telah ditentukan, sehingga kemampuan mahasiswa dalam menyusun perangkat pembelajaran dapat lebih maksimal.

\section{Diskripsi Data Pelaksanaan Tindakan Siklus II}

Data yang diperoleh peneliti terkait dengan peningkatan hasil belajar mahasiswa PGSD dengan modul berbasis konflik kognitif terhadap kemampuan menyusun perangkat pembelajaran IPA SD pada siklus II mampu meningkatkan hasil belajar mahasiswa. Peningkatan hasil belajar mahasiswa dapat dilihat pada tabel 2 sebagai berikut : 
Linda \& Bagus, Peningkatan Hasil Belajar Mahasiswa...

Tabel 2. Hasil Belajar Mahasiswa PGSD Siklus II

\begin{tabular}{|c|c|c|c|}
\hline \multirow{2}{*}{ No } & \multirow{2}{*}{ Nama Siswa } & \multicolumn{2}{|c|}{ Nilai } \\
\hline & & Siklus I & Siklus II \\
\hline 1 & $\mathrm{AF}$ & 50 & 65 \\
\hline 2 & ATF & 40 & 59 \\
\hline 3 & APC & 55 & 63 \\
\hline 4 & CNA & 70 & 79 \\
\hline 5 & DPB & 75 & 81 \\
\hline 6 & $\mathrm{DA}$ & 61 & 76 \\
\hline 7 & FAM & 77 & 87 \\
\hline 8 & GR & 65 & 78 \\
\hline 9 & MR & 77 & 89 \\
\hline 10 & MA & 67 & 78 \\
\hline 11 & MAM & 81 & 92 \\
\hline 12 & MKA & 83 & 93 \\
\hline 13 & OLE & 71 & 78 \\
\hline 14 & RDS & 51 & 67 \\
\hline 15 & RFP & 78 & 84 \\
\hline 16 & SNF & 75 & 84 \\
\hline 17 & $\mathrm{~S}$ & 76 & 83 \\
\hline 18 & TZS & 80 & 83 \\
\hline 19 & WH & 77 & 81 \\
\hline 20 & $\mathrm{HS}$ & 87 & 100 \\
\hline 21 & RAR & 85 & 90 \\
\hline 22 & MNH & 67 & 79 \\
\hline 23 & PRW & 76 & 88 \\
\hline 24 & RANM & 68 & 73 \\
\hline 25 & SO & 80 & 87 \\
\hline 26 & SDP & 81 & 90 \\
\hline 27 & SAR & 83 & 96 \\
\hline 28 & ZKL & 81 & 86 \\
\hline 29 & $\mathrm{SA}$ & 85 & 96 \\
\hline 30 & ESD & 87 & 91 \\
\hline 31 & LI & 60 & 80 \\
\hline 32 & LKK & 67 & 76 \\
\hline 33 & $\mathrm{NH}$ & 75 & 87 \\
\hline 34 & JK & 83 & 90 \\
\hline 35 & WPW & 60 & 78 \\
\hline 36 & LR & 73 & 80 \\
\hline 37 & DLP & 77 & 86 \\
\hline & Rata-rata & 73 & 83 \\
\hline & Tuntas & 22 & 32 \\
\hline & Tidak Tuntas & 15 & 5 \\
\hline & $\begin{array}{l}\text { Presentase } \\
\text { Ketuntasan }\end{array}$ & $59 \%$ & $87 \%$ \\
\hline
\end{tabular}

Berdasakan tabel di atas dapat dilihat bahwa ada peningkatan hasil belajar pada siklus I ke siklus II. Hal ini dapat dilihat dari rata-rata hasil belajar mahasiswa pada siklus I mencapai 73, siklus II nilai rata-rata hasil belajar mahasiswa mencapai 83. 
Linda \& Bagus, Peningkatan Hasil Belajar Mahasiswa...

Selanjutnya Jumlah siswa yang sudah tuntas $\geq 75$ juga mengalami peningkatan, terlihat pada siklus I sebanyak 22 mahasiswa dan pada siklus II sebanyak 32 mahasiswa. Sedangkan persentase ketuntasan hasil belajer mahasiwa juga mengalami peningkatan sebesar 28\%, dimana pada siklus I persentase ketuntasan mahasiswa sebesar 59\% dan pada siklus II mengalami peningkatan menjadi $87 \%$, dengan demikian target penelitian (80\%) sudah terpenuhi.

\section{Observasi Siklus II}

Berdasarkan ahali observasi yang dilakukan pada siklus I diketahui bahwa keterlaksanan pembelajaran didalam kelas sudah maksimal, pemanfaatan modul konflik kognitif sudah berjalan dengan baik sesuai sintak yang telah ditentuka. Kemampuan mahasiswa dalam menyusun perangkat pembelajaran sudah baik.

\section{Refleksi Siklus II}

Kegiatan refleksi bertujuan untuk mengetahui kelemahan dan kelebihan dari kegiatan yang sudah dilaksanakan. Refleksi didasakan pada pengamatan yang dikumpulkan observer. Setelah melakukan pengamatan observer dan peneliti bertemu untuk mendiskusikan hasil pengamatan. Hasil analisis hasil belajar mahasiswa terjadi peningkatan pada nilai rata-rata mahasiswa dan prosentase ketuntasan hasil belajar mahasiswa. Peningkatan dapat dilihat pada tabel 1 dan 2. Peningkatan hasil belajar mahasiswa PGSD dengan modul berbasis konflik kognitif terhadap kemampuan menyusun perangkat pembelajaran IPA SD pada siklus II dapat dinyatakan berhasil sehingga penelitian tindakan kelas dapat dinyatakan selesai.

\section{SIMPULAN}

Dari analisis data dan pembahasan yang telah dikemukanan sebelumnya, peneliti dapat menyimpulkan bahwa penggunaan penggunaan modul berbasis konflik kognitif terhadap kemampuan menyusun perangkat pembelajaran IPA SD dapat meningkatkan hasil belajar mahasiwa. Hasil belajar mahasiswa pada siklus I diperoleh rata-rata 73 dan meningkat menjadi 83 pada siklus II, dengan demikian persentase ketuntasan hasil belajar mahasiswa secara klasikal mengalami peneingkatan sebesar $28 \%$, sedangkan presentase ketuntasan belajar secara klasikal pada siklus I sebesar 59\% meningkat menjadi $87 \%$ pada siklus II.

\section{DAFTAR PUSTAKA}

Akbar, S. \& Sriwiyana, H. 2011. Pengembangan Kurikulum dan Pembelajaran Ilmu Pengetahuan Sosial. Cipta Media: Yogyakarta.

Akbar, S. \& luluk Fz. 2009. Prosedur Penyusunan Laporan Dan Artikel Hasil Penelitian Tindakan Kelas. Yogyakarta: Cipta Media Aksara.

Depdiknas. (2008). Panduan Pengembangan Bahan Ajar. Jakarta: Direktorat Pembinaan Sekolah Menengah Atas. 
Linda \& Bagus, Peningkatan Hasil Belajar Mahasiswa...

Mulyasa. 2010. Praktik Penelitian Tindakan Kelas Menciptakan Perbaikan Berkesinambungan. Bandung: Rosdakarya

Suastra, I. W. (2009). Pembelajaran Sains Terkini: Mendekatkan Siswa dengan Lingkungan Alamiah dan Sosial Budayanya. Singaraja: Universitas Pendidikan Ganesha.

Sugiono. 2010. Statistika untuk Penelitian. Bandung: Alfabeta.

Wahidmurni \& Ali,N. 2008. Penelitian Tindakan Kelas. Malang: Universita negeri malang (UM Press. 